\title{
Is There a Relationship Between Part D Medication Adherence and Part C Intermediate Outcomes Star Ratings Measures?
}

\author{
Jamie T. Ta, BS, PharmD Candidate; Sara C. Erickson, PharmD: \\ Wenyi (Amanda) Qiu, MS; and Bimal V. Patel, PharmD, MS
}

\begin{abstract}
BACKGROUND: Improvements in the Centers for Medicare \& Medicaid Services (CMS) star ratings Part D medication adherence measures may affect performance in Part $C$ intermediate outcome measures for which the Part D targeted medication classes are prescribed.

OBJECTIVE: To determine if Part D medication adherence measures are associated with corresponding Part $\mathrm{C}$ intermediate outcome measures.

METHODS: This was a cross-sectional analysis using the CMS 2015 star ratings report (based on 2013 benefit year plan data) for Medicare contracts. The measures of interest included the Part $D$ adherence measures for diabetes medications, antihypertensive agents, and statins and the Part C intermediate outcome measures for controlled blood sugar, blood pressure, and cholesterol. All Medicare Advantage Prescription Drug (MAPD) contracts with complete data for all Part C and D measures of interest were included. Contracts with $\geq 25 \%$ of total enrollment with MA-only benefit were excluded. Linear and logistic regression models were used to assess the association between 2015 Part $D$ adherence measures and Part C intermediate outcome measures $(n=366)$. The regression models were adjusted for low-income subsidy (LIS) beneficiary enrollment and logtransformed (natural logarithm) total contract enrollment.
\end{abstract}

RESULTS: Bivariate linear regression models demonstrated moderate positive associations between each of the 2015 Part $D$ adherence scores and related 2015 Part C measures that explained $27 \%-29 \%\left(R^{2}\right)$ of variance. Including LIS and total contract enrollment in the regression models increased the $\mathrm{R}^{2}$ to $30 \%-36 \%$. The multivariate logistic regression models showed that each percentage point of improvement in the 2015 Part D adherence measures was associated with a 4.13 to 4.69 greater odds of performing in the top quartile in corresponding 2015 Part $\mathrm{C}$ measures.

CONCLUSIONS: Moderate positive associations were observed between the Part D and Part C scores in the same benefit year. MAPD plans may observe improved Part C intermediate outcome measures with strategies that improve Part D medication adherence measures.

J Manag Care Spec Pharm. 2016;22(7):787-95

Copyright @ 2016, Academy of Managed Care Pharmacy. All rights reserved.

\section{What is already known about this subject}

Centers for Medicare \& Medicaid Services (CMS) have placed an emphasis on several Part C and D measures related to medication therapy by weighting these measures 3 times as much as CMS's process measures.

Randomized and observational studies to date have demonstrated the impact of interventions targeting medication adherence to diabetic medications, antihypertensive agents, and statins on improving blood sugar, blood pressure, and low-density lipoprotein cholesterol control.

A recent analysis has demonstrated the association between health plan measures of adherence and outcomes.

\section{What this study adds}

The results of this study indicate that high ratings in Part D adherence measures are associated with high ratings in related Part C measures.

Health plans may be able to improve multiple star ratings measures and overall plan performance with strategies aimed at improving medication adherence rates.

Ј n 2007, the Centers for Medicare \& Medicaid Services (CMS) developed the star ratings system to measure health L plan performance related to outcomes, patient experience and satisfaction with care, and patient access to health care services. ${ }^{1,2}$ The star ratings system is one of several industry programs aimed at defining quality health care, assessing plan performance in various quality measures, and rewarding positive outcomes. CMS star ratings measures are derived from measures developed and endorsed by various health care quality organizations, including the Pharmacy Quality Alliance (PQA) and the National Committee for Quality Assurance (NCQA) Healthcare Effectiveness Data and Information Set (HEDIS). ${ }^{2}$ CMS assigns numeric scores on individual performance measures (i.e., base-level measures) and assigns 1 to 5 stars to individual measures and groups of related measures to summarize overall performance, with 5 stars indicating excellent performance, 3 stars indicating average performance, and 1 star indicating poor performance. ${ }^{2}$

Plan performance on CMS star ratings measures is of considerable interest to Medicare plan sponsors for several reasons. 
Is There a Relationship Between Part D Medication Adherence and Part C Intermediate Outcomes Star Ratings Measures?

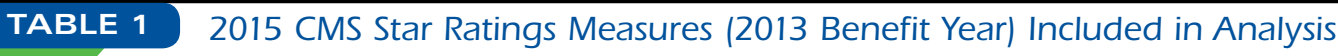

\begin{tabular}{|c|c|c|c|}
\hline Measure Label & Measure Description & Data Source & $\begin{array}{l}\text { Weighting } \\
\text { Value }\end{array}$ \\
\hline $\begin{array}{l}\text { Medication Adherence for } \\
\text { Diabetes Medications }\end{array}$ & $\begin{array}{l}\text { Percentage of beneficiaries aged } 18 \text { years or older with at least } 2 \text { prescription fills } \\
\text { and a PDC } \geq 80 \% \text { for any } 1 \text { of the diabetes medication classes }\end{array}$ & $\begin{array}{l}\text { PDE data, Medicare } \\
\text { EDB file, CWF }\end{array}$ & 3 \\
\hline $\begin{array}{l}\text { Medication Adherence for } \\
\text { Hypertension (RAS Antagonists) }\end{array}$ & $\begin{array}{l}\text { Percentage of beneficiaries aged } 18 \text { years or older with at least } 2 \text { prescription fills } \\
\text { and a PDC } \geq 80 \% \text { for RAS antagonist medications }{ }^{b}\end{array}$ & $\begin{array}{l}\text { PDE data, Medicare } \\
\text { EDB file, CWF }\end{array}$ & 3 \\
\hline $\begin{array}{l}\text { Medication Adherence for } \\
\text { Cholesterol (Statins) }\end{array}$ & $\begin{array}{l}\text { Percentage of beneficiaries aged } 18 \text { years or older with at least } 2 \text { prescription fills } \\
\text { and a PDC } \geq 80 \% \text { for statin medications }\end{array}$ & $\begin{array}{l}\text { PDE data, Medicare } \\
\text { EDB file, CWF }\end{array}$ & 3 \\
\hline $\begin{array}{l}\text { Diabetes Care-Blood Sugar } \\
\text { Controlled }\end{array}$ & $\begin{array}{l}\text { Percentage of plan members aged } 18-75 \text { years with diabetes who had an Alc lab } \\
\text { test that showed controlled blood sugar }(\mathrm{Alc} \leq 9 \%)\end{array}$ & HEDIS & 3 \\
\hline $\begin{array}{l}\text { Diabetes Care-Cholesterol } \\
\text { Controlled }\end{array}$ & $\begin{array}{l}\text { Percentage of plan members aged } 18-75 \text { years with diabetes whose most recent } \\
\text { cholesterol test showed LDL-C }<100 \mathrm{mg} / \mathrm{dL}\end{array}$ & HEDIS & 3 \\
\hline Controlling Blood Pressure & $\begin{array}{l}\text { Percentage of plan members aged } 18-85 \text { years with hypertension whose blood } \\
\text { pressure was adequately controlled }(<140 / 90)\end{array}$ & HEDIS & 3 \\
\hline
\end{tabular}

a Diabetes medication classes include biguanides, sulfonylureas, thiazolidinediones, dipeptidyl peptidase-IV inhibitors, incretin mimetics, and meglitinides. Beneficiaries with 1 or more fills for insulin were excluded.

${ }^{b} R A S$ antagonists include angiotensin-converting enzyme inhibitors, angiotensin receptor blockers, and direct renin inhibitor medications.

Alc=hemoglobin Alc; CMS = Centers for Medicare \& Medicaid Services; CWF=Common Working File; EDB= Medicare Enrollment Database; HEDIS = Healthcare Effectiveness Data and Information Set; $L D L-C=$ low-density lipoprotein cholesterol; $P D C=$ proportion of days covered; $P D E=$ prescription drug event; RAS = renin-angiotensin system.

First, the Affordable Care Act of 2010 entitles high-performing plans to quality bonus payments (QBPs); 3,4 beginning with the 2015 star ratings, only plans with 4 or more stars were eligible for QBPs. ${ }^{4}$ Additionally, star ratings affect Medicare beneficiaries' choices in enrolling in insurance plans. Reid et al. (2013) found an increased likelihood for new Medicare beneficiaries to select plans with higher star ratings and continuing enrollees to switch to plans with higher star ratings. ${ }^{5}$ Medicare enrollment in higher-rated plans is increasing; in 2015, 61\% of Medicare beneficiaries were enrolled in plans with 4 or more stars, a 25\% increase from 2013. ${ }^{6}$ Revenue from QBPs, which are required by Medicare to be used only for providing additional benefits to members, ${ }^{1,3}$ may provide the means for plans to implement additional quality programs and further improve star ratings, which will likely attract more Medicare beneficiaries. Furthermore, contracts with consistently poor plan performance (i.e., rated below 3 stars for 3 consecutive years) receive the low-performing icon on the Medicare Plan Finder website and are subject to termination by CMS in $2016 .{ }^{7}$ Therefore, improvement of star ratings has a potentially significant material effect on plan revenue and market share in the Medicare insurance marketplace.

In 2012, CMS began weighting specific Part C and D measures related to outcomes, intermediate outcomes, and patient access, indicating CMS's greater emphasis on certain quality indicators. ${ }^{1}$ Specifically, CMS's outcome and intermediate outcome measures are highly weighted measures that are weighted 3 times as much as CMS's process measures. ${ }^{1,2}$ For the 2015 star ratings, CMS's triple-weighted measures included Part D medication adherence measures for diabetes medications, renin-angiotensin system (RAS) antagonists, and statins and Part $\mathrm{C}$ measures related to intermediate outcomes commonly associated with these classes of medications: Diabetes Care-Blood Sugar Controlled, Diabetes Care-Cholesterol Controlled, and Controlling Blood Pressure. ${ }^{2}$ The greater contribution of these triple-weighted measures to a plan's Part C and Part D summary ratings and overall star rating creates additional incentives for plans to place emphasis on quality programs aimed at improving medication adherence.

Despite research supporting the association between medication adherence and improved clinical outcomes, there are limited data on the association between plan-level medication adherence and outcomes quality measures. Stakeholder discussions on CMS star ratings measures have suggested the importance of medication adherence in influencing Part C intermediate outcome measures and overall star ratings. ${ }^{1}$ Because of the anticipated effect of medication adherence on achieving positive outcomes from prescribed drug therapy, health plan strategies to target Part D medication adherence measures may potentially affect performance across multiple related Part $C$ intermediate outcomes measures. The purpose of this analysis was to determine if a relationship exists between triple-weighted Part D medication adherence measures and corresponding Part C measures.

\section{Methods}

\section{Study Design and Data Source}

This was a cross-sectional analysis using the CMS 2015 star ratings report that reflected contract performance data for the 2013 benefit year.

CMS publishes Medicare plan performance data each October before the annual open enrollment period on the CMS 


\section{FIGURE 1 2015 Star Ratings Report Medicare} Contracts Included in Analysis

Medicare contracts included in 2015 star ratings report $(n=691)$

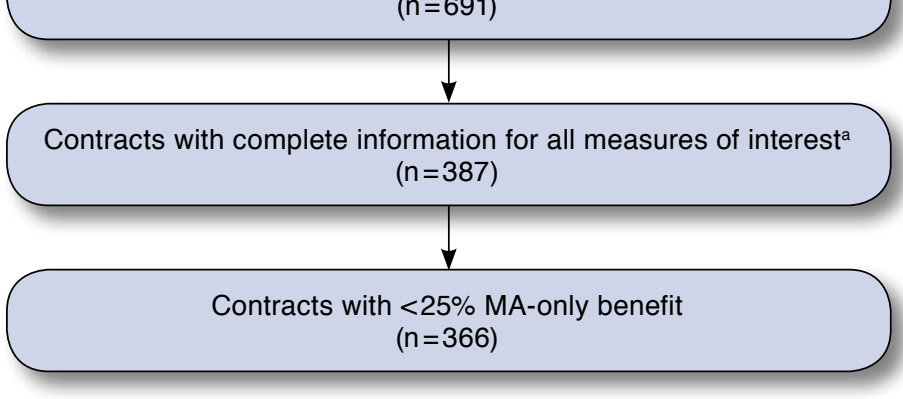

aContracts were excluded if the following were indicated for any of the Part $C$ and D measures of interest: "No data available," "Not enough data available," "Plan too new to be measured," "Plan too small to be measured," or "CMS identified issues with this plan's data."

CMS = Centers for Medicare $E$ Medicaid Services; MA = Medicare Advantage

website. ${ }^{8}$ The star ratings report is named for the upcoming benefit year and reflects plan data from the previous benefit year. For example, the 2015 star ratings report was released in late 2014 and reflects plan performance data for the 2013 benefit year. Performance data are reported at the contract level, and each contract receives a numeric score and a star rating ( 1 to 5 stars) for individual Part $C$ and D star ratings measures. A star rating also is assigned to contracts for groups of related measures (i.e., domains) and for overall performance (i.e., overall star rating). For the 2015 star ratings report, there were 46 measures (33 Part C measures and 13 Part D measures) in 9 domains. ${ }^{2}$ Medicare Advantage (MA) contracts and Prescription Drug Plans (PDPs) are rated based on performance in Part C or Part D measures, respectively, while Medicare Advantage Prescription Drug (MAPD) contracts are rated on all Part $C$ and D measures.

The 2015 star ratings measures of interest for this analysis included the Part D medication adherence measures for diabetes medications, RAS antagonists, and statins and Part C Diabetes Care-Blood Sugar Controlled, Controlling Blood Pressure, and Diabetes Care-Cholesterol Controlled measures (Table 1). Each of the Part D medication adherence measures for the 2015 star ratings report is reported as the percentage of members with fills in the medication class who achieve $80 \%$ proportion of days covered (PDC), or in other words, the percentage of members who fill their prescriptions to cover $80 \%$ or more of the total days of directed medication use. ${ }^{2}$ PDC is an adherence metric that has been developed by PQA and endorsed by the National Quality Forum. ${ }^{2}$ The measure also is being used as a quality measure under the URAC PBM Accreditation and the Quality Rating System for Qualified
Health Plans., ${ }^{910}$ The Part C intermediate outcome measures for the 2015 star ratings report were adopted by CMS from the NCQA HEDIS 2014 Technical Specifications Manual as follows: Diabetes Care-Blood Sugar Controlled (percentage of plan members with diabetes whose most recent hemoglobin Alc [Alc] lab test results showed controlled blood sugar [Alc $\leq 9 \%]$ ); Diabetes Care-Cholesterol Controlled (percentage of plan members with diabetes whose most recent low-density lipoprotein cholesterol [LDL-C] level during the measurement year was less than $100 \mathrm{mg} / \mathrm{dL}$ ); Controlling Blood Pressure (percentage of plan members with a diagnosis of hypertension who achieved adequately controlled blood pressure [<140/90] during the measurement year). ${ }^{2}$ Of the Part $C$ and $D$ measures of interest, the Part C Diabetes Care-Blood Sugar Controlled, Part C Diabetes Care-Cholesterol Controlled, and Part D Medication Adherence for Diabetes Medications measures include only beneficiaries with diabetes, while all other measures include beneficiaries regardless of diabetes diagnosis.

\section{Inclusion Criteria}

All MAPD contracts contained in the 2015 CMS star ratings report that had base-level numeric data for all the Part $C$ and Part D measures of interest were included in this analysis. Contracts with "No data available," "Not enough data available," "Plan too new to be measured," "Plan too small to be measured," or "CMS identified issues with this plan's data" for any of the Part $C$ and $D$ measures of interest were excluded from this analysis. Additionally, since MA plans are not required to report performance in Part D measures, contracts with $25 \%$ or more of total contract enrollment with MA-only benefits were specified a priori to be excluded from the analysis (Figure 1).

\section{Statistical Analysis}

Bivariate linear regressions were performed using each 2015 star ratings Part D measure base-level score as the independent variable and each corresponding Part $C$ base score as the dependent variable to assess the association between Part D and related Part C measures in the 2015 star ratings report (2013 benefit year). The 2015 star ratings measures of interest were collected by CMS in the same measurement period from January 1, 2013, to December 31, 2013. ${ }^{2}$ Multivariate linear and logistic regressions using each Part D measure as the independent variable were used to model the probability of performing in the top quartile of the Part $\mathrm{C}$ measure. Independent variables included total contract size and low-income subsidy (LIS) beneficiary enrollment. Total contract size was transformed using the natural logarithm, which normalized the distribution of contract size. The regression models were performed using SAS version 9.4 (SAS Institute, Cary, NC), and a 2-sided $P$ value of $<0.05$ was considered statistically significant. 
Is There a Relationship Between Part D Medication Adherence and Part C Intermediate Outcomes Star Ratings Measures?

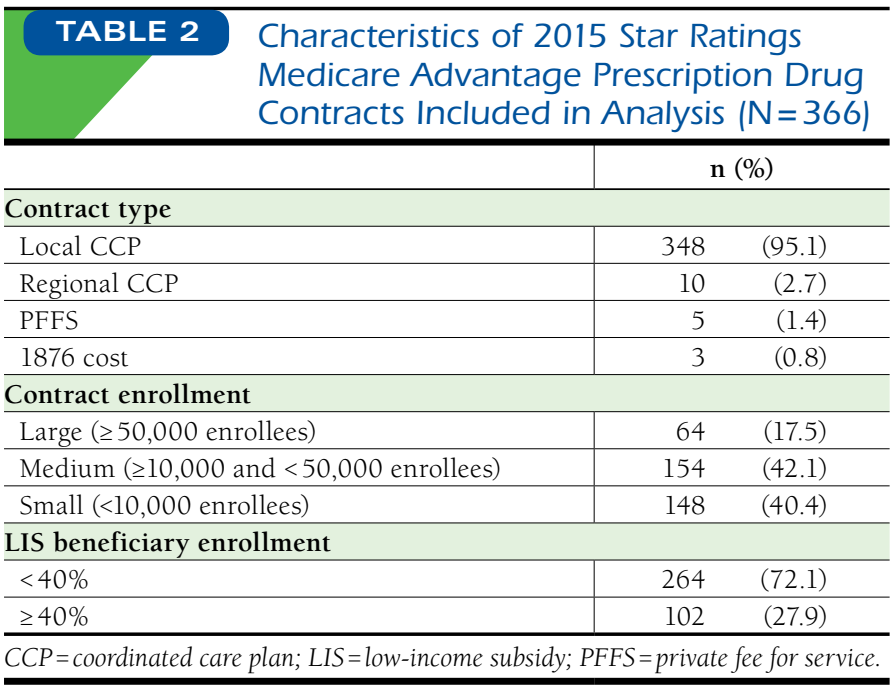

\section{Results}

A total of 366 Medicare contracts were included in the analysis, representing 53\% of the 691 total Medicare contracts meeting criteria. Most contracts were local coordinated care plans (95.1\%), mid-sized ( $\geq 10,000$ and $<50,000$ enrollees, $42.1 \%)$, and had less than $40 \%$ of total enrollment with LIS beneficiaries (72.1\%; Table 2). Mean (standard deviation [SD]) Part D medication adherence base scores for diabetes medications, RAS antagonists, and statins among the 366 contracts included in this analysis were $76 \%(5 \%), 78 \%(5 \%)$, and $73 \%$ (7\%), respectively (Table 3). Mean (SD) base scores for the Part C Diabetes Care-Blood Sugar Controlled, Controlling Blood Pressure, and Diabetes Care-Cholesterol Controlled measures among these contracts were $76 \%$ (11\%), 65\% (11\%), and 54\% $(9 \%)$, respectively (Table 3 ).

The bivariate linear regression models demonstrated moderate positive associations that accounted for $27 \%-29 \%$ of variance between each Part D medication adherence and related Part C measure (Table 4): Diabetes Care-Blood Sugar Controlled $\left(R^{2}=0.29, P<0.001\right)$; Controlling Blood Pressure $\left(R^{2}=0.29\right.$,
$P<0.001)$; and Diabetes Care - Cholesterol Controlled $\left(R^{2}=0.27\right.$, $P<0.001)$. The multivariate regression models adjusted for LIS enrollment and total contract enrollment showed improved associations that accounted for 30\%-36\% of variance between the corresponding measures (Table 5): Diabetes Care-Blood Sugar Controlled $\left(R^{2}=0.36, P<0.001\right)$; Controlling Blood Pressure $\left(R^{2}=0.30, P<0.001\right)$; and Diabetes Care-Cholesterol Controlled $\left(\mathrm{R}^{2}=0.35, P<0.001\right)$.

The logistic regression models adjusted for LIS beneficiary enrollment and the natural logarithm of total contract enrollment showed that for each unit increase of medication adherence, the odds of performing in the top quartile of the corresponding Part $\mathrm{C}$ intermediate outcome measure increased by a factor of 4.63 (95\% confidence interval $[\mathrm{CI}]=2.72-7.89)$, 4.13 (95\% CI =2.44-6.98), and 4.69 (95\% CI=2.79-7.91) for the Controlling Blood Pressure, Diabetes Care-Cholesterol Controlled, and Diabetes Care-Blood Sugar Controlled measures, respectively (Figure 2). High LIS beneficiary enrollment $(\geq 40 \%)$ was associated with decreased odds of performing in the top quartile of the Part $\mathrm{C}$ Diabetes Care-Cholesterol Controlled (odds ratio $[\mathrm{OR}]=0.26,95 \% \mathrm{CI}=0.12-0.53$ ) and Diabetes Care-Blood Sugar Controlled (OR $=0.23$, 95\% $\mathrm{CI}=0.11-0.48)$ measures. Compared with smaller contracts $(<10,000$ enrollees), larger contracts $(\geq 50,000$ enrollees) had increased odds of achieving high base scores for the Part $C$ Controlling Blood Pressure ( $\mathrm{OR}=2.30,95 \% \mathrm{CI}=1.12-4.70)$ and Diabetes Care-Blood Sugar Controlled (OR=2.08, 95\% $\mathrm{CI}=1.03-4.23)$ measures. Mid-size contracts $(\geq 10,000$ and $<50,000$ enrollees), compared with small contracts, did not have significantly greater odds of achieving a high Part C intermediate outcome measure score, except for the Part $C$ Diabetes Care-Blood Sugar Controlled measure (OR $=1.90$, 95\% CI $=1.07-3.36)$.

\section{Discussion}

To our knowledge, this is the first study to examine the relationship between Part D medication adherence and Part C intermediate outcome star ratings measures. This analysis showed moderate positive associations between the 3 Part D

TABLE 3 Summary of 2015 CMS Star Ratings Part D Medication Adherence Measures and Corresponding Part C Intermediate Outcome Measures for MAPD Contracts that Report Complete Data for All Measures of Interest $(\mathrm{N}=366)$

\begin{tabular}{|c|c|c|c|}
\hline Measure Label & Data Time Frame & Base Data Range & Base Mean (SD) \\
\hline Medication Adherence for Diabetes Medications & January 1, 2013-December 31, 2013 & $56 \%-89 \%$ & $(5 \%)$ \\
\hline Medication Adherence for Hypertension (RAS Antagonists) & January 1, 2013-December 31, 2013 & $62 \%-90 \%$ & $(5 \%)$ \\
\hline Medication Adherence for Cholesterol (Statins) & January 1, 2013-December 31, 2013 & $40 \%-86 \%$ & $(7 \%)$ \\
\hline Diabetes Care-Blood Sugar Controlled & January 1, 2013-December 31, 2013 & $27 \%-93 \%$ & $(11 \%)$ \\
\hline Diabetes Care-Cholesterol Controlled & January 1, 2013-December 31, 2013 & $23 \%-84 \%$ & $(9 \%)$ \\
\hline Controlling Blood Pressure & January 1, 2013-December 31, 2013 & $14 \%-92 \%$ & $(11 \%)$ \\
\hline
\end{tabular}

$C M S=$ Centers for Medicare $E$ Medicaid Services; MAPD = Medicare Advantage Prescription Drug plan; RAS = renin-angiotensin system; SD = standard deviation. 
Is There a Relationship Between Part D Medication Adherence and Part C Intermediate Outcomes Star Ratings Measures?

TABLE 4 Bivariate Linear Regression for MAPD Contracts Reporting Complete Data for All 2015 Star Ratings Report Part $C$ and $D$ Measures of Interest ( $N=366)$

\begin{tabular}{|c|c|c|c|c|c|}
\hline 2015 Part D Measure (Independent Variable) & 2015 Part C Measure (Dependent Variable) & $\begin{array}{c}\text { Beta } \\
\text { Coefficient }\end{array}$ & $\begin{array}{c}\begin{array}{c}\text { Standard } \\
\text { Error }\end{array} \\
\end{array}$ & $\mathrm{R}^{2}$ & $P$ Value \\
\hline Medication Adherence for Diabetes Medications & Diabetes Care-Blood Sugar Controlled & 1.056 & 0.086 & 0.29 & $<0.001$ \\
\hline Medication Adherence for Hypertension (RAS Antagonists) & Controlling Blood Pressure & 1.156 & 0.095 & 0.29 & $<0.001$ \\
\hline Medication Adherence for Cholesterol (Statins) & Diabetes Care-Cholesterol Controlled & 0.709 & 0.061 & 0.27 & $<0.001$ \\
\hline
\end{tabular}

$M A P D=$ Medicare Advantage Prescription Drug plan; $R A S=$ renin-angiotensin system; $R^{2}=$ coefficient of determination .

TABLE 5 Multiple Linear Regression Models Adjusted for LIS Beneficiary Enrollment and Natural Logarithm of Total Contract Enrollment for MAPD Contracts Reporting Complete Data for All 2015 Star Ratings Report Part C and D Measures of Interest ( $N=366)$

\begin{tabular}{|c|c|c|c|c|c|}
\hline 2015 Part D Measure (Independent Variable) & 2015 Part C Measure (Dependent Variable) & $\begin{array}{c}\text { Beta } \\
\text { Coefficient }\end{array}$ & \begin{tabular}{|c|} 
Standard \\
Error
\end{tabular} & $\mathrm{R}^{2}$ & $P$ Value \\
\hline Medication Adherence for Diabetes Medications & Diabetes Care-Blood Sugar Controlled & 0.894 & 0.086 & 0.36 & $<0.001$ \\
\hline Medication Adherence for Hypertension (RAS Antagonists) & Controlling Blood Pressure & 1.151 & 0.109 & 0.30 & $<0.001$ \\
\hline Medication Adherence for Cholesterol (Statins) & Diabetes Care-Cholesterol Controlled & 0.640 & 0.059 & 0.35 & $<0.001$ \\
\hline
\end{tabular}

medication adherence measures and the corresponding Part $C$ intermediate outcome measures in the 2015 star ratings report (2013 benefit year). The positive associations found between the Part D and Part C measures are consistent with literature findings that have demonstrated improved LDL-C, blood pressure, and blood sugar control with high levels of adherence (i.e., $\mathrm{PDC} \geq 80 \%$ ) to each of the Part D medication classes. ${ }^{11-14}$ While this analysis found positive associations between Part D adherence and Part C intermediate outcome measures in the same benefit year, this association does not indicate causality. Other factors, such as regular testing and access to better quality care, may contribute to improved performance in Part $\mathrm{C}$ intermediate outcome measures. The absence of strong associations between the Part D medication adherence and Part C intermediate outcome measures also may be accounted for in the differences in the specifications for the Part D and corresponding Part $\mathrm{C}$ measured populations.

The strongest association was observed between the Part D diabetes medication adherence and Part $C$ Diabetes Care-Blood Sugar Controlled measures $\left(R^{2}=0.36, P<0.001\right)$. However, trends in blood sugar control reflected in the Part $C$ measure are not fully explained, possibly because of the exclusion of individuals taking insulin in the Part $\mathrm{D}$ diabetes medication adherence measure. Excluding patients with diabetes taking insulin has been shown to eliminate a large number of beneficiaries in star ratings measures..$^{15}$ In addition, insulin treatment is associated with improved glycemic control, ${ }^{16-18}$ and methods for measuring insulin adherence using the PDC calculation have recently been described. ${ }^{19,20}$ While measuring insulin adherence in patients concurrently receiving noninsulin therapies may introduce additional complexity to diabetes medication adherence measurement in quality measures, unmeasured insulin adherence may confound the observed association between medication adherence for diabetic medications and blood sugar control measured in the Part D and C measures, respectively.

Similarly, the Part D Medication Adherence for Hypertension measure is limited to the measurement of adherence to angiotensin-converting enzyme inhibitors, angiotensin receptor blockers, and direct renin inhibitors, which likely excludes a large number of beneficiaries who receive other antihypertensive treatments. Published studies have noted an increasing use of thiazide-type diuretics (TZDs) and calcium channel blockers (CCBs). ${ }^{21-23}$ Also, recently released guidelines by the Eighth Joint National Committee on the Prevention, Detection, Evaluation, and Treatment of High Blood Pressure (JNC 8) indicate TZDs and CCBs as first-line options for the treatment of hypertension. ${ }^{24}$ In addition, combination regimens consisting of multiple antihypertensive drug classes are commonly required to achieve adequate blood pressure control. Gu et al. (2012) found that individuals in National Health and Nutrition Examination Surveys from 2001 to 2010 receiving multidrug antihypertensive regimens were 26\%-55\% more likely to achieve JNC 7 blood pressure goals compared with individuals receiving monotherapy. ${ }^{21}$ Therefore, the effect of unmeasured adherence to other antihypertensive agents may have a significant contribution to the Part C Controlling Blood Pressure measure performance.

The beneficiary population included in the Part C Diabetes Care-Cholesterol Controlled measure consists of patients with diabetes, while the Part D Medication Adherence for Cholesterol measure includes beneficiaries with 2 or more fills 
FIGURE 2 Logistic Regression Models with Proportion of LIS Beneficiaries, Natural Logarithm of Enrollment Size, and Part D Adherence Measure Score as Predictor Variables

Logistic Regression Model for Controlling Blood Pressure Part C Measure

LIS beneficiaries ( $\geq 40 \%$ vs. $<40 \%)$

Enrollment size

$(10,000-50,000$ vs. $<10,000$ members $)$

Enrollment size ( $\geq 50,000$ vs. $<10,000$ members)

RAS antagonist adherence Part D measure (top quartile vs. lower 3 quartiles)

Logistic Regression Model for Diabetes CareCholesterol Controlled Part C Measure

LIS beneficiaries ( $\geq 40 \%$ vs. $<40 \%$ )

Enrollment size $(10,000-50,000$ vs. $<10,000$ members $)$

Enrollment size ( $\geq 50,000$ vs. $<10,000$ members)

Statin adherence Part D measure (top quartile vs. lower 3 quartiles)

Logistic Regression Model for Diabetes CareBlood Sugar Controlled Part C Measure

$$
\begin{array}{r}
\text { LIS beneficiaries } \\
(\geq 40 \% \text { vs. }<40 \%) \\
\text { Enrollment size } \\
(10,000-50,000 \text { vs. }<10,000 \text { members }) \\
\text { Enrollment size } \\
(\geq 50,000 \text { vs. }<10,000 \text { members })
\end{array}
$$

Diabetes medication adherence Part $D$ measure (top quartile vs. lower 3 quartiles)
Odds ratio $(95 \% \mathrm{Cl})$

$0.55(0.28-1.08)$

$1.50(0.84-2.69)$

$2.30(1.12-4.70)$

$4.63(2.72-7.89)$

$0.26(0.12-0.53)$

$1.67(0.95-2.96)$

$1.96(0.96-4.01)$

$4.13(2.44-6.98)$

$0.23(0.11-0.48)$

$1.90(1.07-3.36)$

$2.08(1.03-4.23)$

$4.69(2.79-7.91)$

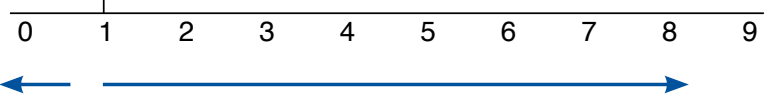

Favors Lower Part C Intermediate

Favors Higher Part C Intermediate Outcome Score 
of statins, regardless of diabetes diagnosis. This subpopulation of beneficiaries with diabetes that is included in the Part C measure may have different characteristics compared with the entire population of statin users included in the Part D statins adherence measure. Statins are also standard of care treatment for patients aged 40-75 years with diabetes regardless of lipid levels. ${ }^{25}$ Patients with diabetes using statins without history of dyslipidemias may confound the association between statin adherence and LDL-C levels.

Adjusting for LIS enrollment and total contract enrollment in the regression models improved the associations between each of the 2015 Part D and Part C measures, and both variables were associated with performance in the Part $\mathrm{C}$ measures. The observed association between LIS enrollment size with star ratings measures is consistent with preliminary analyses conducted by CMS, which have noted a statistically significant negative association between dual/LIS enrollment and performance in a subset of star ratings measures, including the Part C Diabetes Care-Blood Sugar Controlled and Part D adherence measures for diabetes medications, RAS antagonists, and statins. ${ }^{26}$ For these measures, however, the association between dual/LIS enrollment and star ratings measure performance decreased after controlling for disability, ${ }^{26}$ which suggests the potential contribution of additional patient-level factors and other plan demographics in driving the association between star ratings adherence and intermediate outcome measures. Additionally, our finding that larger contracts have an increased odds of achieving a higher Part $C$ score is consistent with a previous report by Xu et al. (2015), which found that large contract size, maturity, and nonprofit status were associated with higher star ratings for MAPD contracts. ${ }^{27}$

Despite CMS's emphasis on these triple-weighted Part D medication adherence and Part C intermediate outcome measures, improvement of these measures is typically challenging for health plans because of the need for greater member engagement in order to achieve positive outcomes. ${ }^{1}$ Efforts to improve medication adherence likely require a multidimensional approach, innovative strategies, and high-touch interventions, such as clinician case management. Effective interventions have emerged from strategic partnerships between health plans, pharmacy benefit managers (PBMs), and pharmacies. A comprehensive pharmacy intervention using PBM pharmacy claims data, member outreaches by a health plan care management team, and mail order pharmacy delivery of medications led to significant improvements in performance in all Part D medication adherence measures for a dual-eligible Medicare Special Needs Plan. ${ }^{28}$ Randomized and observational studies to date have demonstrated the impact of interventions, including personalized pharmacist consultations and patient education, targeting medication adherence to diabetes medications, antihypertensive agents, and statins on improving blood sugar, blood pressure, and LDL-C control. ${ }^{29,30}$ Additionally, a recent analysis of private health plan claims data by Seabury et al. (2015) demonstrated the association between higher average adherence rates and lower hospitalization rates in plan-level quality measures. ${ }^{31}$ The cumulative evidence suggests that strategies in improving medication adherence are also likely to improve intermediate outcome quality measures.

\section{Limitations}

This analysis contains the following limitations. First, approximately $47 \%$ of Medicare contracts present in the 2015 CMS star ratings report were excluded from this analysis because of the incomplete reporting of base-level numeric data for all Part C and D measures of interest. New and low enrollment contracts - defined by CMS as contracts with less than 1,000 enrollees for 2015 star ratings measures that are derived from HEDIS $^{2}$ - did not report data for all the Part C and D measures of interest and were therefore excluded from this analysis. This lack of reporting may limit the applicability of the results if new or low enrollment contracts have different characteristics than those in our sample.

Second, the applicability of these results is limited by changes affecting the Part C and D measures of interest for the 2016 star ratings report (2014 benefit year). Following the release of the new American College of Cardiology/American Heart Association Guidelines on the Treatment of Blood Cholesterol, as well as the retirement of 3 NCQA measures related to LDL-C control for HEDIS 2015, CMS has retired the Part C Diabetes Care-Cholesterol Controlled measure for the 2016 star ratings. ${ }^{7,32}$ Also, in response to the release of the JNC 8 Guideline for the Management of High Blood Pressure, ${ }^{7}$ CMS has modified the methodology of the Part C Controlling Blood Pressure measure to reflect the percentage of beneficiaries aged 18-59 years and 60-85 years with diabetes who have a blood pressure reading of $<140 / 90$ and members aged $60-85$ years without diabetes who have a blood pressure reading of $<150 / 90$ during the measurement year. ${ }^{32}$

In relation to Part D measures, sodium glucose cotransporter 2 inhibitors will be included in the diabetes medication adherence measure, and beneficiaries with end-stage renal disease coverage will be excluded from the Part $\mathrm{D}$ adherence measures for diabetes and hypertension medications. ${ }^{32}$ These methodological changes may result in higher performance, on average, across contracts in these Part C and D measures for the 2016 star ratings. For HEDIS-derived Part $\mathrm{C}$ measures that include all the Part $\mathrm{C}$ intermediate outcome measures of interest, CMS has redefined low-enrollment contracts to include contracts with $\geq 500$ enrollees, 7,32 which would result in more contracts being eligible for inclusion in the 2016 star ratings Part $\mathrm{C}$ measures. 
Also, the actual beneficiary date of death or disenrollment, instead of the last day of the month of disenrollment, will be used to define the end of the beneficiary's measurement period for the PDC adherence calculation, although this likely will have minimal impact on adherence rates and performance in the Part D measures. ${ }^{7,32}$ Future studies should assess the impact of these changes on the association between Part C and D measures in future star ratings reports.

Third, the PDC calculation used in the Part D adherence measures may not fully capture adherence to combination therapy. Limitations in the PDC methodology may be especially important for the Part D Medication Adherence for Diabetes Medications measure. Specifically, the PDC calculation may appear to artificially inflate adherence in the Part D Medication Adherence for Diabetes Medications measure, since this measure requires the supply of only 1 diabetes medication in the measurement period. Despite these limitations, PDC has been shown to be a reliable indicator of drug exposure and predictive of measurable clinical outcomes in diabetes, hypertension, and hyperlipidemia. ${ }^{12,14}$

Fourth, this study used publicly available Medicare contract performance results that are reported at the contract level and do not include demographic or patient-level data. As a result, we were not able to control for socioeconomic differences in patient populations other than LIS beneficiary enrollment. More research is needed to understand the association between Part D and C measures in the context of an intervention where patient-level data are available.

Finally, this study focused on the Medicare-eligible elderly population. Therefore, the results of this analysis may not be generalizable to other plan populations, such as commercial plans on federal or state exchanges and Medicaid populations outside of dual-eligible plans.

\section{Conclusions}

In the context of national stakeholder discussions promoting the importance of medication adherence in influencing Part C intermediate outcome measures related to medication therapy, ${ }^{1}$ the findings of this study indicate that MAPD plan sponsors may experience improved performance in Part $C$ measures with strategies that improve performance in Part D medication adherence measures. This analysis suggests the potential added value of improving medication adherence in influencing Part $C$ intermediate outcome measures and overall plan performance. Plan sponsors may use this information to guide strategies for achieving higher star ratings. The association between triple-weighted Part D medication adherence measures and Part $C$ measures underscores the importance of innovative quality improvement strategies aimed at improving medication adherence.

\section{Authors}

JAMIE T. TA, BS, PharmD Candidate, University of California, San Diego, Skaggs School of Pharmacy and Pharmaceutical Sciences, La Jolla, California, and Specialty Pharmacy Research Assistant, MedImpact Healthcare Systems, San Diego, California. SARA C. ERICKSON, PharmD; WENYI QIU, MS; and BIMAL V. PATEL, PharmD, MS, MedImpact Healthcare Systems, San Diego, California.

AUTHOR CORRESPONDENCE: Jamie T. Ta, BS, PharmD Candidate, UCSD Skaggs School of Pharmacy and Pharmaceutical Sciences, 9500 Gilman Dr., La Jolla, CA 92093. Tel.: 858.790.5645; E-mail: jtta@ucsd.edu.

\section{DISCLOSURES}

This study was conducted by MedImpact Healthcare Systems, San Diego, California, without external funding. All authors are employees of MedImpact Healthcare Systems. Erickson reports advisory board fees from Sanofi and AstraZeneca.

Ta, Erickson, and Patel were responsible for study concept and design and data interpretation, with assistance from Qiu. Qiu and Ta took the lead in data collection, assisted by Erickson. Ta wrote the manuscript, which was revised by Erickson and Patel.

\section{REFERENCES}

1. Academy of Managed Care Pharmacy, American Pharmacists Association. Medicare star ratings: stakeholder proceedings on community pharmacy and managed care partnerships in quality. J Am Pharm Assoc (2003).

2014;54(3):228-40. Available at: http://www.japha.org/article/S15443191(15)30180-1/fulltext\#s0090. Accessed June 1, 2016.

2. Centers for Medicare \& Medicaid Services. Medicare 2015 Part C \& D star rating technical notes. In: 2015 Part C \& D Medicare star ratings data (v4 16 2015). Available at: http://www.cms.gov/Medicare/Prescription-DrugCoverage/PrescriptionDrugCovGenIn/PerformanceData.html. Accessed June 1, 2016.

3. Jacobson G, Neuman T, Damico A, Huang J. Medicare Advantage plan star ratings and bonus payments in 2012. Data Brief. Kaiser Family Foundation. November 2011. Available at: http://kaiserfamilyfoundation.files.wordpress com/2013/01/8257.pdf. Accessed June 1, 2016.

4. Centers for Medicare \& Medicaid Services. Advance notice of methodological changes for calendar year (CY) 2015 for Medicare Advantage (MA) capitation rates, Part C and Part D payment policies and 2015 call letter. February 21, 2014. Available at: https://www.cms.gov/Medicare/HealthPlans/MedicareAdvtgSpecRateStats/downloads/Advance2015.pdf. Accessed June 1, 2016.

5. Reid RO, Deb P, Howell BL, Shrank WH. Association between Medicare Advantage plan star ratings and enrollment. JAMA. 2013;309(3):267-74. Available at: http://jama.jamanetwork.com/article.aspx?articleid=1557733. Accessed June 1, 2016.

6. Jacobson G, Damico A, Neuman T, Gold M. Medicare Advantage 2015 spotlight: enrollment market update. Issue Brief. Kaiser Family Foundation. June 30, 2015. Available at: http://kff.org/medicare/issue-brief/medicareadvantage-2015-spotlight-enrollment-market-update/. Accessed June 1, 2016

7. Centers for Medicare \& Medicaid Services. Announcement of calendar year (CY) 2016 Medicare Advantage capitation rates and Medicare Advantage and Part D payment policies and final call letter. April 6, 2015. Available at: https://www.cms.gov/medicare/health-plans/medicareadvtgspecratestats/ downloads/announcement2016.pdf. Accessed June 1, 2016. 
8. Centers for Medicare \& Medicaid Services. Part C and D performance data. Available at: https://www.cms.gov/medicare/prescription-drug-coverage/prescriptiondrugcovgenin/performancedata.html. Accessed June 1, 2016.

9. URAC. Pharmacy benefit management measures. Measures at a glance. February 26, 2015. Updated March 28, 2016. Available at: https://www. urac.org/wp-content/uploads/PBM_Measures_AtAGlance_02-26-2015.pdf. Accessed June 1, 2016.

10. Centers for Medicare \& Medicaid Services. Quality rating system measure technical specifications. September 2015. Available at: https:// www.cms.gov/Medicare/Quality-Initiatives-Patient-Assessment-Instruments/ QualityInitiativesGenInfo/Downloads/2016-QRS-Measure-TechnicalSpecifications.pdf. Accessed June 6, 2016.

11. Shalev V, Goldshtein I, Halpern Y, Chodick G. Association between persistence with statin therapy and reduction in low-density lipoprotein cholesterol level: analysis of real-life data from community settings. Pharmacotherapy. 2014;34(1):1-8.

12. Bramley TJ, Gerbino PP, Nightengale BS, Frech-Tamas F. Relationship of blood pressure control to adherence with antihypertensive monotherapy in 13 managed care organizations. J Manag Care Pharm. 2006;12(3):239-45. Available at: http://amcp.org/data/jmcp/Research_239-245.pdf.

13. Ho PM, Rumsfeld JS, Masoudi FA, et al. Effect of medication nonadherence on hospitalization and mortality among patients with diabetes mellitus. Arch Intern Med. 2006;166(17):1836-41. Available at: http://archinte.jamanetwork.com/article. aspx?articleid=410956. Accessed June 1, 2016.

14. Rozenfeld Y, Hunt JS, Plauschinat C, Wong KS. Oral antidiabetic medication adherence and glycemic control in managed care. Am J Manag Care. 2008;14(2):71-75. Available at: http://www.ajmc.com/journals/ issue/2008/2008-02-vol14-n2/Feb08-2832p071-075/. Accessed June 1, 2016.

15. Schmittdiel J, Raebel M, Dyer W, et al. Medicare star excludes diabetes patients with poor CVD risk factor control. Am J Manag Care. 2014;20(12): e573-81. Available at: http://www.ajmc.com/journals/issue/2014/2014vol20-n12/Medicare-Star-Excludes-Diabetes-Patients-With-Poor-CVD-RiskFactor-Control/. Accessed June 1, 2016

16. Holman RR, Thorne KI, Farmer AJ, et al. Addition of biphasic, prandial, or basal insulin to oral therapy in type 2 diabetes. N Engl J Med. 2007;357(17):1716-30. Available at: http://www.nejm.org/doi/full/10.1056/ NEJMoa075392\#t=articleTop. Accessed June 1, 2016.

17. Davis KL, Tangirala M, Meyers JL, Wei W. Real-world comparative outcomes of U.S. type 2 diabetes patients initiating analog basal insulin therapy. Curr Med Res Opin. 2013;29(9):1083-91.

18. Donnelly LA, Morris AD, Evans JM; DARTS/MEMO collaboration. Adherence to insulin and its association with glycaemic control in patients with type 2 diabetes. QJM. 2007;100(6):345-50. Available at: http://qjmed. oxfordjournals.org/content/100/6/345.long. Accessed June 1, 2016.

19. Eby EL, Van Brunt K, Brusko C, Curtis B, Lage MJ. Dosing of U-100 insulin and associated outcomes among Medicare enrollees with type 1 or type 2 diabetes. Clin Interv Aging. 2015;10:991-1001. Available at: http:// www.ncbi.nlm.nih.gov/pmc/articles/PMC4476426/. Accessed June 1, 2016

20. Lee LJ, Li Q, Reynolds MW, Pawaskar MD, Corrigan SM. Comparison of utilization, cost, adherence, and hypoglycemia in patients with type 2 diabetes initiating rapid-acting insulin analog with prefilled pen versus vial/ syringe. J Med Econ. 2011;14(1):75-86.

21. Gu Q, Burt VL, Dillon CF, Yoon S. Trends in antihypertensive medication use and blood pressure control among United States adults with hypertension: the National Health and Nutrition Examination Survey, 2001 to 2010. Circulation. 2012;126(17):2105-14. Available at: http://circ.ahajournals. org/content/126/17/2105.long. Accessed June 1, 2016.
22. Stafford RS, Monti V, Furberg CD, Ma J. Long-term and short-term changes in antihypertensive prescribing by office-based physicians in the United States. Hypertension. 2006;48(2):213-18. Available at: http://hyper. ahajournals.org/content/48/2/213.long. Accessed June 1, 2016.

23. Gu Q, Paulose-Ram R, Dillon C, Burt V. Antihypertensive medication use among US adults with hypertension. Circulation. 2006;113(2):213-21. Available at: http://circ.ahajournals.org/content/113/2/213.long. Accessed June 1, 2016.

24. James PA, Oparil S, Carter BL, et al. 2014 Evidence-based guideline for the management of high blood pressure in adults: report from the panel members appointed to the Eighth Joint National Committee (JNC 8). JAMA. 2014;311(5):507-20. Available at: http://jama.jamanetwork.com/article. aspx?articleid=1791497. Accessed June 1, 2016.

25. Stone NJ, Robinson JG, Lichtenstein AH, et al. 2013 ACC/AHA guideline on treatment of blood cholesterol to reduce atherosclerotic cardiovascular risk in adults: a report of the American College of Cardiology/American Heart Association Task Force on Practice Guidelines. J Am Coll Cardiol. 2014;63(25 Pt B):2889-934. Available at: http://content.onlinejacc.org/article. aspx?articleid=1879710. Accessed June 1, 2016 .

26. Centers for Medicare \& Medicaid Services. Examining the potential effects of socioeconomic factors on star ratings. September 8, 2015. Available at: http://www.cms.gov/Medicare/Prescription-Drug-Coverage/ PrescriptionDrugCovGenIn/Downloads/Research-on-the-Impact-ofSocioeconomic-Status-on-Star-Ratingsvl-09082015.pdf. Accessed June 1, 2016

27. Xu P, Burgess JF Jr, Cabral H, Soria-Saucedo R, Kazis LE. Relationships between Medicare Advantage contract characteristics and quality-of-care ratings: an observational analysis of Medicare Advantage star ratings. Ann Intern Med. 2015;162(5):353-58.

28. Leslie RS, Tirado B, Patel BV, Rein PJ. Evaluation of an integrated adherence program aimed to increase Medicare Part D star rating measures. J Manag Care Spec Pharm. 2014;20(12):1193-203. Available at: http://www. jmcp.org/doi/abs/10.18553/jmcp.2014.20.12.1193.

29. Lee JK, Grace KA, Taylor AJ. Effect of a pharmacy care program on medication adherence and persistence, blood pressure, and low-density lipoprotein cholesterol: a randomized controlled trial. JAMA. 2006;296(21):2563-71. Available at: http://jama.jamanetwork.com/article. aspx?articleid=204402. Accessed June 1, 2016.

30. Spence MM, Makarem AF, Reyes SL, et al. Evaluation of an outpatient pharmacy clinical services program on adherence and clinical outcomes among patients with diabetes and/or coronary artery disease. J Manag Care Spec Pharm. 2014;20(10):1036-45. Available at: http://www.jmcp.org/doi/ abs/10.18553/jmcp.2014.20.10.1036.

31. Seabury SA, Lakdawalla DN, Dougherty JS, Sullivan J, Goldman DP. Medication adherence and measures of health plan quality. Am J Manag Care. 2015;21(6):e379-89. Available at: http://www.ajmc.com/journals/ issue/2015/2015-vol21-n6/Medication-Adherence-and-Measures-of-HealthPlan-Quality/. Accessed June 1, 2016.

32. Centers for Medicare \& Medicaid Services. Medicare 2016 Part C \& D star rating technical notes. In: 2016 Part C \& D Medicare Star Ratings Data (v04 07 2016). Available at: https://www.cms.gov/medicare/prescriptiondrug-coverage/prescriptiondrugcovgenin/performancedata.html. Accessed June 6, 2016. 